\title{
How Nonemployer Firms Stage-Manage Ad-Hoc Collaboration: An Activity Theory Analysis
}

\author{
Clay Spinuzzi \\ The University of Texas at Austin
}

\begin{abstract}
Nonemployer firms — firms with no employees—-present themselves as larger, more stable firms in order to take on clients' projects. They then achieve these projects by recruiting subcontractors, guiding the subcontractors' interactions with clients, and coordinating subcontractors in ways that protect their team performance for the client. Using fourth generation activity theory, I examine how these firms stagemanage their ad-hoc collaborations. I conclude by describing the implications for further developing fourth-generation activity theory to study such instances of knowledge work.
\end{abstract}


Published in Technical Communication Quarterly 23(2), (2014), pp. 88-114;

DOI:10.1080/10572252.2013.797334

\section{Introduction}

Imagine that you represent a company that wants a new identity system (logo, business cards, letterhead, website design, etc.). You go to an advertising and design agency, where you meet the project lead and her team. Together, you and the team discuss your needs, then the team puts together a timeline and writes up an agreement. Throughout, the design team strives to appear professional: unified, competent, imaginative, trustworthy, and able to execute your project within the parameters to which you've agreed. Their office is the front stage for this performance. And their fate is bound up with their performance: as fulltime employees, these performers know that if they don't get your business, they may lose their jobs.

But services such as design and advertising, which once required considerable overhead, no longer do; work that once required a studio full of equipment can now be done with laptops and mobile phones. That fact has impacted how teams work. For instance, many design agencies are now actually nonemployer firms (NEFs): self-employed individuals or small partnerships whose firm has no paid employees, has business receipts over $\$ 1,000$, and is subject to federal income taxes (United States Small Business Association Office of Advocacy 2011). NEFs typically take on a client, then enlist a temporary network of subcontractors to handle parts of the client's job. These subcontractors could be anywhere - in town or across the globe - and they may not have even met the NEF. Just as importantly, unlike traditional employees, these subcontractors work in multiple networks and have multiple income streams; they know that if they don't perform well, at worst, they may lose one of these many streams of income. Their fate is not necessarily bound up in their performance for any one contractor.

If you decided to hire an NEF, however, you may not even realize the difference. NEFs rarely advertise the fact that they have no employees or that the client's project exceeds their in-house capacity or skill. As far as the client is concerned, the NEF is a black box (Latour 1987), appearing to be a much larger, more stable organization. At the same time, NEFs are more nimble than larger organizations, and are thus able to provide customized services at lower cost. When you hire an NEF to design your identity system, "back stage" the NEF puts together a temporary, customized team of subcontractors to focus on your specific project; at the end of the project, they disperse, perhaps never to work as a team again. But from your point of view "front stage," you contracted a firm (not an individual) to create your identity system, and you are not surprised when the firm delivers it on time and under budget, just like any other firm. Indeed, as we'll see in this study, the NEFs I studied worked hard to project the image of larger firms. NEFs manage to succeed and often even excel in such performances, presenting their temporary, flexible, ad hoc network as having the stability and capabilities of a larger firm. That's remarkable, since a rotating set of subcontractors poses a number of threats to the NEF's performance: The NEF must acquire the right subcontractors for each job; coordinate them properly with a variety of texts; trust them to do their work; establish proper communication between them and the clients without disrupting the appearance of stability; and ensure that they do not embarrass the NEF. And they must do all this with what they describe as minimal leverage over their subcontractors. How do they handle such performances? That is, how do they establish the front stage, manage the "casting call” for their subcontractors, and coordinate the backstage in order to perform as a larger firm?

To investigate these questions, I first examine changes in work organization and discuss how to theorize these changes in terms of collaboration (in the broad sense of working together to achieve a goal). Next, using a fourth-generation activity theory framework, I describe two studies of NEFs in Austin, Texas, examining how they report constructing their front stage performance, enlisting 
Published in Technical Communication Quarterly 23(2), (2014), pp. 88-114;

DOI:10.1080/10572252.2013.797334

subcontractors to perform, and coordinating their back stage to stage manage their performance. Finally, I discuss implications for better understanding and analyzing team performances in temporary networks.

\section{Background}

\section{The Growth of Nonemployer Firms}

We've seen strong growth in NEFs, thanks in part to long-term employment trends (e.g.,BurtonJones, 2001; Castells, 2003; Malone, 2004; Zuboff \& Maxmin, 2004) and developments in mobile technology. These developments have led to more work from remote locations, more distance collaboration, and more work that is organized around temporary projects (what is sometimes called projectification ; see Midler 1995; Grabher 2002, 2004; Guile 2012). Various forms of distributed work (Spinuzzi, 2007) have been on the rise, including independent contracting and other forms of contingent labor (BurtonJones, 2001); nomadic work, in which individuals travel frequently (Mark \& Su, 2010; Su \& Mark, 2008); distance work and telework (Bradner \& Mark, 2002; Paretti, McNair, \& Holloway Attaway, 2007), and peer production work (Benkler, 2006; Mueller, 2010). One recent industry report estimates that "the modern contingent labor umbrella encompasses over $22 \%$ of the average organization's total workforce” (Dwyer, 2011, p.2).

These employment trends favor the growth of nonemployer firms. Consequently, NEFs have increased in the United States, especially in Austin. For instance, in 20022008, the number of these firms has increased by $21 \%$ in the United States-and by $41 \%$ in the Austin Round Rock Metropolitan Area. In the information sector, which includes “(a) producing and distributing information and cultural products, (b) providing the means to transmit or distribute these products as well as data or communications, and (c) processing data” (United States Census Bureau 2011a), NEFs have grown remarkably in number (64\% in the Austin Round Rock Metropolitan Area vs. 32\% in the United States) and in receipts (105\% in the Austin Round Rock Metropolitan Area vs. 46\% in the United States) (United States Census Bureau 2011b). These changes all far outpace the population change in the Austin Round Rock Metropolitan Area (22.2\%) and the United States (5.8\%) during the same period (United States Census Bureau 2011c). And despite the economic difficulties that began in late 2008, Austin led the nation in small business growth in 20082009 with a 0.43 percent growth rate: it was one of only three major markets in the United States to add small businesses during that time (Austin Business Journal 2011).

Beyond the employment trends, other factors have been favorable to NEF growth. For instance, consumer level information and communication technologies have both improved and dropped in price; thus work that once required a desktop computer and a fixed-line telephone-such as graphic desig n or technical writing - can now be accomplished with less expensive, more mobile technologies such as laptops, mobile phones, and consumer-grade wireless broadband. In addition, since these technologies are mobile, NEFs often avoid the overhead of a leased office or studio by working out of home offices, coffee shops, co-working spaces, or other low-cost spaces. Another factor is that professionals have found strong motivations to strike out on their own, such as autonomy and the ability to work flexible hours (characteristics that distinguish this sort of work from more traditional form s of contracting, such as builder contracting or movie making; cf. Zuboff \& Maxmin 2004).

But to flourish, NEFs must take on jobs that are sometimes too large or too complex for one person or partnership to handle. For instance, a graphic designer might take on a project that involves redesigning a client's website-a project that involves skills she does not have (web development, photo retouching, copywriting) and more work than she has time to do. Consequently, NEFs must assemble networks of subcontractors to which they subcontract for capacity (that is, to offload work they do not have time to do) and for skill (that is, to perform work outside their expertise). (Grabher 2004 calls these "project ecologies.") To take on and execute jobs reliably, they must have access to a 
Published in Technical Communication Quarterly 23(2), (2014), pp. 88-114;

DOI:10.1080/10572252.2013.797334

large enough network of subcontractors. When an NEF considers taking on a job, the first question she must answer is: Can I find reliable people in these specialties who I can trust to perform quality work within this timeframe and budget?

Sociologist Manuel Castells (1996, 2009) has argued that such developments are symptoms of a transition to a "network society" in which people organize their work through ad hoc networks of individuals. These networks are created not just to communicate but to outcommunicate. They are adaptive, open-ended and multiedged (p.65) and and are meant to circulate information, which has become the product of the production process (p.65; 172). Technical writing, graphic design, and web development are examples of professions whose products are information.

Networks particularly characterize "e-business," in which business uses the Internet "as a fundamental medium for communication and information-processing" and thus "adopts the network as its organizational form" (Castells 2003, p.66). In e-business, "business practice is performed by ad hoc networks" which "have the flexibility and adaptability required by a global economy subjected to relentless technological innovation and stimulated by rapidly changing demand" (p.67). Here, "the new production system relies on a combination of strategic alliances and ad hoc cooperation projects between corporations, decentralized units of each major corporation, and networks of small and medium enterprises connecting among themselves and/or with large corporations or networks of corporations" (2003, p.96, 100; cf. Castells 1993, p.18; Zuboff \& Maxmin 2004).

The circulation of people drives innovation in the network society (Castells 1996, p.95), which is characterized by the "flexibility and instability of work, and the individualization of labor" (Castells 1997, p.1). In particular, the network society demands more flexible labor, which takes the form of parttime, temporary, and self-employed work (1997, p.173). Flexible workers give up the stability and assurance of fulltime employment, but they gain autonomy, which they pursue "not necessarily to increase monetary gains but to enjoy greater freedom, flextime, or more opportunity to create" (2006, p.10). Castells (2003) specifically points to operationally autonomous labor in small businesses and consultant-subcontractor networks: "These business entrepreneurs own their means of production (a computer, a telephone line, a mobile phone, a place somewhere, often at home, their education, their experience, and, the main asset, their minds)” (p.92; cf. Drucker 1994).

How does this reconfiguration affect how NEFs in subcontractor networks present themselves to clients? How do they take on the challenge of appearing big but being small? Although Castells' work provides us with a broad understanding of how work organization is changing, it does not provide us with a developmentally oriented framework for examining how individuals collaborate, set goals, and solve problems through collaboration. Here, I turn to fourth-generation activity theory (4GAT), which has recently developed to respond to the issues that Castells and others have raised.

\section{Analyzing NEFs with a Fourth-Generation Activity Theory Framework}

Like its predecessor, third-generation activity theory (3GAT), 4GAT provides a developmentally oriented account of work: it examines activity systems in which actors cyclically use instruments to cyclically achieve a shared object(ive) (Russell 1997). But 3GAT tends to focus on situations that are more common in agricultural or industrial work: single activity systems with clearly defined consensual object(ive)s, and (more recently) somewhat multiperspectival object(ive)s that are the meeting places for different activities. Thus 3GAT has not been well equipped to deal with situations that are more common in knowledge work, such as collaboration and coordination across multiple activities. In response to such concerns - and often in explicit response to Castells' foundational work on defining the knowledge society (e.g., Nardi, Whittaker, \& Schwarz 2002; Yamazumi 2009)—activity theorists have worked on developing a fourth generation of activity theory (Daniels et al. 2010; Sannino et al. 2009; see Spinuzzi 2011 for an overview.) In 4GAT, the object(ive) is inherently multiperspectival, polycontextual, and transient, and the actors' collaborations typically involve heavy boundary-crossing in what are often temporary collaborations across networks of interrelated activities. 
Published in Technical Communication Quarterly 23(2), (2014), pp. 88-114;

DOI:10.1080/10572252.2013.797334

Fourth-Generation activity theorists have specifically developed activity theory to better accommodate Castells' and others' insights into how work organization has shifted. For instance, Yamazumi (2009, p.212) argues that the knowledge society has shifted from mass production to interorganizational collaboration, a shift that results in "new types of agency [that] are collaborations and engagements with a shared object in and for relationships of interaction between multiple activity systems [i.e., activity networks]" (p.213). Yrjö Engeström similarly argues that "social production requires and generates bounded hubs of concentrated coordination efforts” (Engeström 2009, p.310), hubs in which inter-organizational collaboration is the object, or at least a large aspect of the object, of the shared activity (cf. Adler \& Heckscher 2007; Gygi \& Zachry 2010; Spinuzzi 2012). That is, 4GAT analyzes internetworked activities by examining the inter-organizational collaborations to which they contribute. Thus, 4GAT focuses less on the workings of individual activity systems (often represented by triangles) and more on the interactions across activity systems functioning in networks.

Crucially, in knowledge work, such collaborations, engagements, and bounded hubs involve actors whose interests and backgrounds frequently diverge. One example - the example we will consider in this article-is that of NEFs, which operate by assembling ad hoc teams of subcontractors to collaborate on transforming a temporary, multiperspectival object(ive).

In the rest of this article, I first describe two small-scale studies of NEFs that I conducted. Next, I analyze the findings. Finally, I discuss implications of the research.

\section{Methods}

These two qualitative case studies were approved by the institutional review board at the author's institution. Based on Smagorinsky's (2008) suggestions for developing the methods section, I describe the research questions; describe the participants; and describe the data collection and analysis procedures.

\section{Research Questions}

In this study, I sought to answer the following research questions about how nonemployee firms (NEFs) represented their work to clients. In 4GAT terms, I was concerned with how NEFs in both studies maintained the activity networks linking their subcontractors and clients:

- How did NEFs represent themselves to clients? That is, what rules did NEFs establish to govern relationships between their subcontractor network and the client? More broadly, how did they describe the shared object to which NEFs, subcontractors, and client were oriented?

- How did NEFs find and establish relationships with subcontractors who could support their self-presentation to clients? That is, what rules did NEFs establish to build and govern their relationships within the subcontractor network, particularly rules oriented toward the "front stage" facing the client?

- How did NEFs coordinate subcontractors in ways that reinforced rather than disrupted their self-presentation to clients? That is, how did NEFs establish and maintain a division of labor within the subcontractor network so that it did not threaten the link between that network and the client?

\section{Sites and Participants}

In Study 1, a colleague and I visited two graphic design NEFs that initially had no employees and worked out of their residences. (By the second set of observations and interviews, one of the NEFs had rented office space and hired employees.) In Study 2, I interviewed five self-employed individuals who worked in various aspects of web development: developing interactive sites, managing site development projects, writing content, and designing site aesthetics. See Table 1.

(Insert Table 1 about here.) 
Published in Technical Communication Quarterly 23(2), (2014), pp. 88-114;

DOI:10.1080/10572252.2013.797334

\section{Data Collection}

Given the number of sites and the difficulty of setting up interviews with people who have busy and fluid schedules, I collected data snapshots rather than longitudinal data. These data snapshots focused on how the firms reported presenting themselves to clients and how they coordinated with subcontractors.

The word reported is important here, since much of the data come from my interviews with the NEFs rather than direct observations. Although I conducted short observations at worksites in Study 1, these proved impractical in Study 2 due to the participants' extremely flexible schedules and mobile work patterns. In no cases could I observe their meetings with clients, since my presence itself would threaten their performance. Consequently, I relied primarily on participants' statements, which I then triangulated with their self-representations in public artifacts (see the Data Analysis subsection below).

For Study 1, which spanned July 2007August 2008, I collected the following qualitative data:

Interviews . I interviewed participants twice; initial interviews took about 30 minutes and followup interviews took about 20 minutes.

Observations . I observed each NEF twice, for 1 hour each. Given the brevity of these observations, I used them primarily as a way to spark interview questions.

Artifacts . I collected 32 artifacts, including NEF websites, photos (during observations), and LinkedIn and Twitter profiles. I used these artifacts primarily to triangulate participants' interviews with how they represented themselves to clients.

For Study 2, which spanned AugustOctober 2010, I collected the following qualitative data:

Interviews . I interviewed each participant once; interviews ranged from 20-45 minutes, averaging 28 minutes.

Artifacts . I collected 31 artifacts, including NEF websites, LinkedIn and Twitter profiles, Yelp and Google Places pages when available, and collateral materials related to how participants proposed, contracted, and managed projects.

Appendix A lists a selection of artifacts from both studies.

\section{Data Coding}

After collecting the data, I transcribed all interviews, resulting in paragraph-separated units: 281 for Study 1 and 837 for Study 2. I placed each study's data in a relational database, with tables for participants, interviews, artifacts, and (for Study 1) observations. Each datum (database entry) could be assigned multiple codes. For each study, I coded entries using the following procedures.

Starter codes . I began coding deductively, using descriptive starter codes (Miles \& Huberman 1994, pp. 5758). For Study 1, the starter codes were based on activity theory’s implications for knowledge work (Spinuzzi 2008, Ch.7). For Study 2, the starter codes were based on my semistructured interview questions, which in turn were grounded in activity theory concepts.

Open coding . In open coding (Corbin \& Strauss 2008), I inductively identified recurrent themes, defined codes based on them, then checked these codes deductively based on these definitions. I first developed open codes based on specific issues discussed during interviews, then applied them to related data in the other data types. For codes related to texts and tools, I initially autocoded (applied codes based on keywords in the interview text), then added codes to applicable entries that did not share the keywords. I interspersed autocoding with developing open codes , treated as emergent and recursive (Corbin \& Strauss, 2008).

Axial coding . Finally, I performed axial coding (Corbin and Strauss 2008) to draw connections across starter and open codes. To develop axial codes, I looked for codes that appeared together frequently, then used a single code to articulate the relationship among them, developing a specific description for that code. I then recoded all data for those axial codes, applying it to each piece of data that fit the description.

Study 1's axial codes, such as Face and Trust, informed open codes for Study 2. Similarly, after completing Study 2 coding, I recoded Study 1's data by applying some open codes from Study 2.

Data reduction . In identifying recurrent themes, coding also allowed me to reduce the data by focusing on heavily coded data and on data related to key themes. 
Published in Technical Communication Quarterly 23(2), (2014), pp. 88-114;

DOI:10.1080/10572252.2013.797334

Selected codes are listed and described in Appendix B.

\section{Data Analysis}

As mentioned above, I primarily collected interview data, meaning that the participants were undoubtedly performing for me as well as the clients. Although I have no suspicion that they misled me, I recognize that I viewed their "front stage.” Methodologically, I handled this issue by triangulating the interview data with artifacts such as collateral materials as well as (in Study 1) with observations.

To analyze the data, I followed these procedures:

Comparisons . I tested relationships between codes by examining whether they were supported by multiple data sources. I triangulated in the following ways:

Across data types, same NEF . This comparison involved examining how the same phenomenon was treated in interviews, artifacts, and (for Study 1) observations at a given NEF. For instance, I examined how a given NEF represented itself to clients in its website and LinkedIn profile, then compared those with their interview statements about self-representation.

Within data types, across NEFs . This comparison involved examining how the same phenomenon was treated within a given data type across sites. For instance, I examined how all NEFs reported representing themselves to clients.

Member checks . After interviews were transcribed, I conducted a transcription check with each participant to gather comments and feedback. After writing the draft of this article, I gathered manuscript comments from participants.

\section{Findings}

\section{The Front Stage: How do NEFs Represent Themselves to Clients?}

I really am representing [subcontractors' work] as my own work to the client. Because it's more seamless. I mean, not like it's a lie because I am very responsible for the work. So there's no blaming the freelancer anymore. (Sophie)

Sophie is in business by herself, running her graphic design firm (which we'll call “GD1”) from her home office. But her website and collateral materials repeatedly used "we" to describe her business. Like the other NEFs, Sophie reported that she had to construct and maintain a particular representation for her firm: one that allowed it to project the capacity and skill of a larger firm, and therefore engender the trust of clients. To do that, Sophie chose to represent subcontactors' work as coming from GD1 - and consequently, GD1 took both the praise and the blame for their work. What does an NEF's performance look like? How does each NEF perform as a single organization? The NEFs I studied reported using various strategies to achieve this.

\section{Presenting Collateral Materials}

All of the NEFs promoted themselves on their websites and social networking sites-especially LinkedIn—not as individuals, but as firms. For instance, NEFs' professonal titles suggested that they headed larger organizations: "principal” (Sophie), "president” (Albert, Benny), and "owner” (Bob and Tom, Cory, Denise). Of the NEFs, only Ed presented himself as an individual agent on his LinkedIn page. But even Ed used "we” on his company's website and stated that "we are a team." In addition, the NEFs' websites - even Ed's - never stated how large their firms were. In fact, Cory's original website listed two employees in addition to himself; when I asked him about this, he confessed that they were a regular subcontractor and an intern, and that he had added them "to look a little more professional, I guess, so I'm not the only one on the site.” Similarly, Ed's site stated that he "works with” two others. 
Published in Technical Communication Quarterly 23(2), (2014), pp. 88-114;

DOI:10.1080/10572252.2013.797334

\section{Stage-Managing Client Interactions}

NEFs also tended to tailor their interactions with clients to engender trust and to cultivate a professional persona. For instance, in Study 1, during the first observation Sophie told a client on the phone that she could not meet that afternoon because she had a conflicting meeting; in her interview, she confessed that the "meeting" actually entailed taking her preschooler to the library. Sophie also avoided meeting clients in her home office. But she did meet often with clients, using a range of techniques for trust-building in meetings, including choosing a seat near the head of the table and taking notes even when they were not necessary. Similarly, Bob and Tom avoided meeting clients in their office, which was in the dining room of Bob’s condo. All participants in Study 1 reported "tailoring” their demeanor for clients, as Sophie put it.

The graphic designers in Study 1 depended on face-to-face meetings, a vital strategy since they focused on local work. But in Study 2, the participants were involved in aspects of web design. Thus their clients were sometimes local (e.g., Denise, Ed), often regional (e.g., Albert, Benny, Cory), and sometimes out-of-state (e.g., Ed). Although participants reported some face-to-face meetings for local work, for much local and regional work and all out-of-state work they relied on conference calls and email with clients. For instance, Cory reported that for about a third of his engagements, he never even met clients; for the other two thirds, he engaged in initial and concluding meetings but rarely saw clients otherwise. Thus, in Study 2, participants reported and demonstrated client interaction strategies that tended to focus on producing electronic texts (websites, LinkedIn profiles, emails) as well as managing conference calls.

Importantly, since NEFs believed that they had to look big while being small, when they involved subcontractors in client interactions they had to heavily stage-manage that involvement. This Stage-managing took several forms. For instance, when Bob and Tom (who were partners in a small design firm we'll call "GD2") trusted a subcontractor to interact properly with clients, they would give that subcontractor a GD2 email address strictly for those interactions. Albert reported that when he worked with one trusted local designer, he would allow that designer to take part in conference calls and make promises to the client within a particular set of parameters. Benny also allowed subcontractors on conference calls, though reluctantly and only when their expertise exceeded his. Cory had his subcontractors relay questions through him rather than allowing them direct access to clients. Sophie typically did not discuss subcontractors at all, but when she was preparing for a vacation, she transparently connected her client to a trusted subcontractor. Albert, Bob and Tom reported allowing subcontractors to interact with clients through a project management system.

\section{Stage-Managing Mistakes}

Since NEFs chose to keep the black box closed, representing themselves as firms rather than individuals, they reported that they also had to absorb the blame for mistakes the subcontractors made-since blaming subcontractors would entail opening the black box and exposing the internals of the subcontractor network, undermining their self-representationas firms. As Sophie put it, there's "no blaming the freelancer.” Indeed, Sophie, Benny, Cory, and Ed all had stories about having to cover for subcontractors' mistakes and failings. In Benny's case, he had hired one subcontractor who made a "bonehead" mistake-promising functionality that turned out to be too immature to deploy on the customer's website- forcing Benny to "go back to the client and beg for forgiveness and hope that I'm not going to get sued." In Ed's case, he hired a friend, only to find that the friend made an unreliable partner:

I can't ever afford to let that happen to me again. I had two clients that were pissed off about this guy. I had two clients that fired me because of this guy, because of his inability to deliver. They were very unhappy clients, and I have never had unhappy clients before. So it was not a mistake I would want to repeat. (Ed)

Yet NEFs reported that they had little leverage over poorly performing subcontractors during 
Published in Technical Communication Quarterly 23(2), (2014), pp. 88-114;

DOI:10.1080/10572252.2013.797334

the engagement. Not only were subcontractors not part of the formal organization, they also had multiple income streams because of the nature of their work, meaning that the NEF could threaten only a small part of their income. On the other hand, this arrangement made the NEF's team much more flexible. As Sophie explained, compared with working in a formal organization, "It's a lot easier to [terminate a relationship] with a freelancer. 'Cause you can just say, yep, we're wrapping this up [early], just send me your files and [bill me for the work completed]. You don't even have to tell them why."

NEFs, then, had to be able to trust their subcontractors to put on an adequate team performance, and without the leverage that a formal organization has over its fulltime employees. In the next section, I discuss how they built this trust.

\section{The Front Stage: A 4GAT Analysis}

As we've seen, these NEF did not represent stable teams. In fact, that was their strength: each NEF maintained low overhead and high flexibility by assembling a custom team for each project. But this strength was also a weakness, since NEFs believed that they had to present themselves to clients as a company - a relatively stable team that has the capabilities, skill, and coordination necessary to deliver the client's product on time and with the appropriate specifications. In 4GAT terms, each NEF had to bend its efforts toward transforming two distinct but interrelated object(ive)s: its front stage performance and the project that the NEF had been contracted to complete. (Importantly, previous activity theory analyses have examined front stage object(ive)s (e.g., Spinuzzi 2012) and project object(ives)s (e.g., Guile 2012), but few if any have examined them in relationship.) Figure 1 shows how different organizational activities (the triangles) link to two object(ive)s, which involve different people, practices, and timescales; the box represents the blackboxing that the NEF applies to its network of subcontractors (Figure 1).

(Insert Figure 1 about here.)

The front stage performance . The NEFs spent considerable time maintaining and transforming the object(ive) of the front stage performance. This performance was meant for clients and involved projecting the impression of a more stable team (compare Spinuzzi 2012). That front stage performance was carried out online and offline, through collateral materials (generally descriptive texts such as websites) and interactions (communicative acts and texts, such as meetings and emails). Importantly, this object(ive) was often a long-term object(ive), since any client could decide to hire or refer the NEF in the future. Although any given performance might be fleeting, the NEF had to be prepared for encores. That is, the front stage performance would often outlast the project-oriented Black box, i.e., the network of subcontractors who worked on a given project. The NEF thus tended to avoid involving the subcontractors directly in front stage work-although sometimes a few trusted subcontractors would be asked to help stage the performance when necessary (represented by the dotted arrow in Figure 1).

The project . In contrast, the second object(ive) is the specific and sharply delineated project each NEF was hired to solve: the website, the brochure, the magazine redesign. It is a far more transient object(ive), lasting only for the duration of this engagement, perhaps only for a week. Each NEF had to assemble a black-boxed network of subcontractors around this object(ive) in order to complete it, subcontractors that shared this object(ive) but saw different aspects of it: the copy to be written, the back-end website to be coded, the layout to be designed (compare Adler 2007; Guile 2012; Yamazumi 2009). As Figure 1 shows, this object(ive) was mutual to the client, NEFs, and subcontractors; all had a hand in transforming it (even if not all parties were aware of each other). The project object(ive) had roughly the same lifespan as the black box that the NEF erected to support it.

These two object(ive)s did not necessarily contradict each other, but they did not naturally support one another either. Whereas a more stable organization maintains its front stage with a more or less permanent cast, an NEF's performance was more like a play with a different cast every night, a play in which cast members could ad lib and in which they had little stake in the success of the director. 
Published in Technical Communication Quarterly 23(2), (2014), pp. 88-114;

DOI:10.1080/10572252.2013.797334

Each cast member-each subcontractor - had the potential to disrupt the performance. Furthermore, bear in mind that Figure 1 is actually an oversimplification, since each NEF had multiple clients and thus multiple projects and front stages, all of which were daily threatened with disruption. How did NEFs avoid such disruptions, keeping the two object(ive)s aligned? The NEF had to labor to achieve yet a third object(ive), as we'll see in the next section.

\section{The Casting Call: How do NEFs Find and Establish Relationships with Subcontractors who can Support their Self-representation to Clients?}

[I met one copywriter] at a seminar. And just happened, when she contacted me, I was like, "Hey, I do need a copywriter." The second one, who I've used a number of times, is a copywriter that's actually in my networking group. (Albert)It's really because everything is so trust- and relationship-based in this business. I can't just say

"You're a bonehead. You just screwed me." (Benny)

As Albert suggests, NEFs have several avenues for meeting subcontractors, including not only local networking events and serendipitous meetings but also market alternatives such as oDesk and Craigslist ads that allow them to reach a global labor pool. But as Benny relates, this flexibility is a double-edged sword: how does an NEF select the right subcontractors, especially when they have so little leverage over them? The question is critical since, as we saw in the last section, the NEF must absorb the blame if the team performance fails. Where do NEFs seek subcontractors, what criteria do they use, and how do they establish the trust with subcontractors that can allow them to turn out an acceptable team performance?

\section{Where NEFs Find Subcontractors}

Castells (1997) argues that the network society is characterized by the "flexibility and instability of work, and the individualization of labor" (p. 1; see also Castells 2009). NEFs and their subcontractors have traded stability for flexibility and autonomy (Castells 2006). (For instance, Sophie reports that she started her NEF so she could have the flexibility to spend time with her family, while Albert relishes being his own boss.) But that instability means that NEFs must pull together ad hoc teamsfortoday. The NEFs I interviewed mentioned the following strategies for finding subcontractors: networking, affinities, referrals, and market solutions.

Networking . Like Albert, most of the NEFs mentioned using professional contacts that they developed through networking groups, jellies (informal coworking sessions), special interest groups, previous engagements and previous coworkers. They especially used this strategy for locally based work that involved local nuances.

For instance, in Study 1, Sophie, Bob and Tom all reported subcontracting out to people with whom they had worked previously (at a publisher and an advertising firm, respectively). In Study 2, Albert, Benny, Denise, and Ed all reported subcontracting people they had met via professional networking opportunities. Such opportunities allowed the NEFs to prescreen subcontractors by getting a sense of how they worked with others in the network. As Denise put it, she looked for "people who [at least share a] referral network and we've kind of shared clients with each other."

Affinities . Beyond professional networking, some NEFs reported looking to nonprofessional affinities. For instance, in Study 1, Sophie only worked with people she considered friends: "it's hard to just hire somebody out of the blue if you don't really know them and this job's gotta get done, and I mean even if you have a great recommendation, that's a scary thing to do.” In her member check, Sophie added that her criteria for friendship and subcontractors were similar, and these criteria also described her ideal clients: "I'm friends with people with whom I share similar values about respectfulness and responsibility. Basically, if I don't like and trust someone enough to come over to my house and hang out with me and my son, I also don't want my design project hanging out with 
Published in Technical Communication Quarterly 23(2), (2014), pp. 88-114;

DOI:10.1080/10572252.2013.797334

them.” (In contrast, Bob and Tom did not consider their subcontractors to be friends; at one point, Tom described their web developer as a “douchebag.”) In Study 2, Ed also reported subcontracting someone who he had considered trustworthy because of their friendship—although that trust unfortunately turned out to be unfounded.

Friendship was not the only affinity. In Study 2, Cory reported meeting subcontractors through a Christian organization. One of these subcontractors became a close friend and consequently became Cory's chief subcontractor. Similarly, Benny reported meeting a designer when they were waiting to pick up their children from school.

Referrals . The five participants in Study 2 all reported subcontracting based on referrals. For Albert, Benny, Cory, and Ed, a trusted party's referral was typically enough-although Benny, Cory, and Ed each reported being burned by a subcontractor who did not live up to the reference. Denise was more cautious: "I had someone recommended and I'm going to meet with her soon, in the next few days. See some of her work and maybe look at some client references. Check her out on LinkedIn.” Study 1 participants did not report using referrals.

Market solutions . Finally, participants in Study 2 reported sometimes turning to market solutions for finding appropriate subcontractors. Albert and Ed took advantage of global arbitrage by outsourcing some technical jobs to "the Philippines" (Ed) and "Poland, Pakistan, the Philippines, and St. Louis” (Albert), either directly (Ed) or via the virtual workteam service oDesk (Albert). Albert clarified that he typically used market solutions for technical work, while reserving "creative things such as graphic design or copywriting" for local contacts "because I feel that it really helps with the nuances.” Benny reported finding a subcontractor by taking out a Craigslist ad. Study 1 participants did not report using market solutions.

\section{How NEFs Build Trust with Subcontractors}

As noted earlier, NEFs reported having little leverage over their subcontractors, who have other income streams and often only a temporary relationship with the NEF. This arrangement, although ideal for quickly forming and dissolving teams, poses problems for team performances. As Tom put it in Study 1,

I think that's a lot more difficult with contract labor, because contract laborers don't necessarily have a vested interest in your company. I mean, they have a vested interest in doing the best work they can to get paid, but there's not an investment in the company itself. (Tom)

Without the traditional recourse available to managers in institutions - threatening to demote or fire workers-NEFs had to rely on swiftly developing trust. As Adler \& Heckscher (2007) argue, the traditional form of community in corporations has been that of a community of loyalty-a community that (a) is founded on long-term employment and (b) tends to involve personal relations that are "linked to the hierarchy, rather than cutting across it” (p.33). In contrast, a knowledge-intensive economy needs teamwork based on principles, teamwork that involves "swift trust," not blind trust (p.34). Developing swift trust is complex:

In a collaborative order people may be working on multiple tasks and initiatives with multiple accountabilities, and they frequently find themselves in situations where they are pulled in several directions at once. The ability to manage these tensions is one of the key capabilities required of individuals. (p.52)

Further, people must understand the functions, contributions, and values of their partners in other parts of the organization (p.53). That is, workers must become more interdependent, and that new ethic is creating strains just as the emergence of the industrial revolution did: "it demands the ability to interact in multiple communities and to adapt to competing demands of interdependence” (p.54).

The NEFs reported establishing trust, which was so vital to maintaining their front stage, through previous engagements or relationships, background research, agreements, social capital generated during the engagement, and reviews. 
Published in Technical Communication Quarterly 23(2), (2014), pp. 88-114;

DOI:10.1080/10572252.2013.797334

Previous engagements or relationships . First, they sought out subcontractors who they knew from previous engagements or relationships: previous subcontractors or coworkers, people along whom they had served as subcontractors, friends, and those with whom they shared a network. As we've seen, these previous engagements and relationships are one of the main avenues for finding subcontractors in the first place, but they also serve as a key way to assess and lend trust to subcontractors.

Sophie reported that friendship was the key criterion in trusting a subcontractor:

Well, really, the people that I work with as freelancers are also friends ... And it's hard to just hire somebody out of the blue if you don't really know them and this job's gotta get done ... even if you have a great recommendation, that's a scary thing to do. (Sophie)

Like Sophie, Cory and Ed reported hiring friends - though Ed found that this strategy could also fail. As he told me after recounting one problematic subcontractor,

I just really need to be really cautious about who I bring in on a project. Bring in somebody I can really trust. ... The guy was my friend, but I can look back now and see there were warning signs that he might not be a really good worker. (Ed)

In contrast, Bob and Tom relied more heavily on previous work experience. Most of their subcontractors had been coworkers at the ad agency where they had worked previously. Similarly, Denise reported considering subcontractors based on previous projects in which she and the subcontractor had both bid and/or worked together: these projects allowed her to assess their work, but also their interpersonal skills and honor, maturity, and reliability.

When an NEF did not have direct experience with a subcontractor, he or she would sometimes rely on other relationships. For instance, Denise reported that she would consider "people who [at least share a] referral network and we've kind of shared clients with each other.” Albert, Benny, and Ed also described variations of this strategy, considering friends of friends, contacts of contacts, and members of professional societies. This strategy helped them to preselect for reliability and professional skills to some extent, but it also meant a small degree of leverage, since an NEF could make a negative experience known to the network from which the referral came.

Background research . For such referrals, some NEFs did additional background research on recommended subcontractors. For instance, Denise planned to check a subcontractor's client references, examine her work, and scrutinize her LinkedIn. Similarly, Bob and Tom carefully checked the portfolio of each prospective subcontractor.

Agreements . One way to deal with the lack of leverage in subcontracting might be to have subcontractors sign formal contracts. However, none of the NEFs reported using these with subcontractors (although some signed contracts with customers). NEFs certainly took on risk by not requiring formal contracts, but they saved time and legal fees, and perhaps more importantly, they were able to put together teams faster and more flexibly. So, instead of formal contracts, NEFs used what Albert and Benny both characterized as handshake agreements. (Benny ruefully added that "a handshake doesn't mean what it used to anymore.”)

Social capital during the engagement . Trust is a two-way street. So, during the engagement, NEFs reported practicing various forms of trust-building. For instance, Albert and Benny both reported developing inter-loyalty with subcontractors by paying promptly and sometimes even ahead of schedule. As Albert put it, "I think that by paying people promptly and fairly, then I think that when you ask them to be a little bit more flexible, then they are willing to do that." In some cases, such as when he works with a steady and trusted subcontractor, "then I'll go ahead and pay fifty percent up front, I'll go ahead and pay him 100 percent, because I have a good relationship with him, I know he's not going to jet on me.” Because he does this, Albert can occasionally ask this subcontractor to work without an advance when "things are a little lean."

Reviews . After the engagement, NEFs reported sometimes taking recourse in the only form of leverage they had: reviewing the subcontractor. Benny reported that he intended to apply this leverage 
Published in Technical Communication Quarterly 23(2), (2014), pp. 88-114;

DOI:10.1080/10572252.2013.797334

to a problematic subcontractor: "If anybody asks me, I will give him the bad review. 'But don't hire him, you'll be sorry.' And so, you break your trust, then you deserve what you get.” Yet NEFs did not express confidence that this method of recourse would be successful.

\section{The Casting Call: A 4GAT Analysis}

As we've seen, NEFs reported having very little leverage over these flexible, autonomous subcontractors, all of whom pursue multiple income streams, all of whom may never work with the NEF again. This arrangement threatened both of the object(ive)s we've seen so far: the front stage performance and the project.

To protect both of these object(ive)s, the NEFs had to enlist and interest (in the sense of interesse ; see Latour 1999) subcontractors and convince them to support the NEF's object(ives). Finding the right people was tricky — as we've seen, even friends could let an NEF down — but they only had to make this arrangement work for the duration of the project. Thus the NEFs had developed strategies for recruiting and building trust with subcontractors who could support them with yet another object(ive): collaboration.

As Adler \& Heckscher (2007) argue, collaboration (in the broad sense of working together to achieve a goal) was a persistent object(ive) in knowledge work organizations. Even in these ad hoc organizations, which have the lifespan of a mayfly, collaboration served as a third object(ive) that serves to align the other two object(ives). See Figure 2.

(Insert Figure 2 about here.)

Figure 2 adds this third object(ive) of collaboration. Like the front stage performance, collaboration is a more persistent object(ive) than the project itself. As NEFs and subcontractors built trust with each other, they developed relationships that often resulted in multiple projects—and occasionally in bad reviews. (Engestrom (2008) describes such persistent trans-project relationships under the heading of mycorrhizae.) The collaboration object(ive) helps to align the other two object(ive)s, keeping the transitory project coherent with the long-term front stage performance. In the absence of other, more transactional forms of leverage, collaboration had to interesse the subcontractor network.

The object(ive) of collaboration was critical, then, and the NEFs' "casting calls" focused on finding the right collaborators. But to achieve the collaboration, they had to also execute. And that brings us to the next issue.

\section{The Back Stage: How do NEFs Coordinate Subcontractors in Ways that Reinforce Rather than Disrupt their Self-representation to Clients?}

So if somebody said, "Well we need a website, but we also really need a logo because our old logo is crap ... And we don't have anyone to write content for this website so can you do that.” So I would ... reach out to my copywriter, my designer, and my developer, and say, "OK guys, here's the project.” And we would all sit down together, generally over Skype or something like that, and go through the project and all the items and figure out from each person. OK. My portion is this and it's going to take me these many hours to do it, and I'll throw it all out on a spreadsheet basically. OK, here is this person's column, here is this person's column...Here's their hourly rate at the bottom. And I can show you all of this if you want to see it. (Benny)

Benny did indeed show me the spreadsheet, to which we'll return in a moment. As Benny indicated, NEFs had to coordinate extensively behind the scenes to lead their subcontractors in a team performance. How did they coordinate their subcontractors?

This question was critical, since poor coordination could badly disrupt the team's performance. As Cory lamented about one subcontractor, "It was supposed to be like four hours ... and it took him like two to three months." Ed similarly reported that one subcontractor "overcommitted himself because he 
Published in Technical Communication Quarterly 23(2), (2014), pp. 88-114;

DOI:10.1080/10572252.2013.797334

wasn't just doing my work, he had other work he was doing. And he couldn't get all the work done. So, he would let projects slide.” One subcontractor could hold up an entire project. To avoid that problem, NEFs turned to coordinative texts and back stage meetings.

\section{Texts to Control Team Coordination}

As the face of the organization — and the one with the most to lose - the NEF had to coordinate the team's work. As Albert put it, "it's my job ... to send them out to the subcontractors, to hire the right people, to make sure that the graphic designer is aware of the schedule, of the timeline. Make sure that he know that, hey, we are going to have a conference call on this date.” The NEFs used a range of texts to coordinate their teams: project management software; spreadsheets, forms, and notes; and emails and instant messages.

Project management software . Many NEFs chose to use project management software. For instance, Albert, Bob and Tom used Basecamp, while Denise used Privia, which was specialized proposal management software. Bob and Tom also used OmniFocus for tracking tasks. (Although Ed had Project Management Professional certification, he did not mention using project management software.) As Albert explained, project management software served as a way to communicate the project's parameters without micromanaging the subcontractors-and it doubled as a communication medium. Similarly, Bob and Tom sometimes brought clients into their Basecamp project so that the clients could see GD2's progress.

Spreadsheets, printed forms, and notes . Those NEFs who did not mention project management software tended to use other tools to coordinate tasks. For instance, Benny used a spreadsheet (Figure 3) to coordinate the tasks that his team worked. Cory used sticky note software to track basic tasks that his contractors were completing. Finally, Sophie tracked tasks by filling out printed forms.

(Insert Figure 3 about here)

Emails and IM . Beyond communicating with subcontractors, Cory reported using his email inbox for tracking progress. Bob and Tom coordinated with their contractors over instant messaging.

\section{Backstage Meetings}

In addition to texts, and often in concert with them, NEFs frequently conducted backstage meetings with their subcontractors. In these backstage meetings, NEFs coordinated work-often in informal ways - but also built relationships and trust that served to fine-tune the team's performance.

These meetings sometimes happened over telecommunications and sometimes in person.

Skype or phone conversations . NEFs reported conducting direct phone calls (Albert, Benny, Cory, Sophie, Bob and Tom), conference calls (Benny, Denise), and Skype conversations (Benny) to coordinate subcontractors, especially when they were not local. Such conversations often focused on how to divide the labor and develop the timeline. For instance, Benny reported that at the beginning of a project, he would assemble his team on Skype, discuss the project, then record the tasks and time estimates on a spreadsheet (Figure 3). The finished document served to coordinate the project and set client expectations.

Meetings . For local subcontractors, NEFs sometimes conducted face-to-face meetings (Denise, Ed, Sophie, Bob and Tom). For instance, in Study 1, I observed Sophie meeting with a subcontractor at her dining room table, where they went over and discussed client documents, then planned tasks and timeline. Sophie also used the meeting to coach her subcontractor extensively on how to present herself to the client - that is, she used the backstage meeting to coordinate the front-stage performance. 
Published in Technical Communication Quarterly 23(2), (2014), pp. 88-114;

DOI:10.1080/10572252.2013.797334

\section{The Back Stage: A 4GAT Analysis} collaboration's

Recruiting trustworthy collaborators is a necessary step, but insufficient to ensure the success. The subcontractor network must form a back stage so that they can effectively coordinate that collaboration, producing both the project and the front stage performance. The tighter the coordination and the more trust they share, the more likely the NEF is to succeed at achieving — and aligning — all three object(ive)s.

To achieve that coordination, these NEFs have developed rules (including strategies) and tools (including texts). As many in professional communication have argued (Gygi \& Zachry 2010; Russell 1997; Swarts 2006, 2007), such rules and tools have played key roles in coordinating complex activity systems and extended networks of activity.

In the present studies, these rules and tools include portraying subcontractor work as the NEF's own; restricting client-subcontractor interactions; stage-managing subcontractors during conference calls; and using texts such as project management systems and spreadsheets to set and enforce deadlines. Many of these moves affect all three object(ive)s simultaneously: improving the back stage collaboration itself, ensuring that the project will be done on time and with high quality, and minimizing threats to the NEF's longterm front stage performance. And as I mentioned earlier, this alignment is quite complex: each NEF may be black-boxing and coordinating multiple sets of subcontractors as it works on multiple projects from multiple clients. Under such circumstances, it is remarkable that NEFs manage to coherently control their self-presentation.

\section{Implications}

Throughout this article, I have used 4GAT to analyze the complex ways in which NEFs must run — and perform - their businesses. In the broad scheme, such performances are not new (cf. Goffman, 1959). Yet the specific strategies are: they respond to recently emerging capabilities and organizational structures (Engestrom 2009; Guile 2012; Yamazumi 2009). NEFs must master such strategies if they are to effectively coordinate a network of subcontractors and use it to achieve at least three interrelated object(ive)s.

These strategies involve representing a temporary organization as a permanent one to clients; recruiting competent and interested subcontractors who can support that self-representation; and coordinating those subcontractors effectively. The strategies collectively achieve three object(ive)sobject(ive)s that all involve the NEF, but that work at different timescales, require different actors, and involve different tools and rules (cf. Grabher 2004). Although these object(ive)s are different, they do not necessarily contradict each other — a difficult achievement, one that the NEF has to work hard at producing.

Here, 4GAT makes a key contribution by describing this coordination of overlapping object(ive)s in constantly changing configurations. This contribution to this analysis distinguishes

4GAT from previous versions of activity theory, which assume more stable work configurations oriented toward consensual object(ive)s (see Spinuzzi 2011). Stable work configurations will be with us for the foreseeable future, to be sure, but the trends suggest that they will increasingly interact with more mutable configurations such as in the case described here. Those configurations' new structures, capabilities, enabling technologies and collaborative patterns will produce new contingencies and new threats to work; 4GAT is one framework for better studying them, providing one way to separate and study the different object(ives) involved in its team performances. 
Published in Technical Communication Quarterly 23(2), (2014), pp. 88-114;

DOI:10.1080/10572252.2013.797334

\section{Acknowledgements}

I thank the participants in these two studies, who were exceedingly generous with their time. I also thank William HartDavidson and Mark Zachry for providing feedback on earlier drafts; TCQ editor Amy Koerber; and the two anonymous TCQ reviewers, whose comments improved the manuscript considerably. Finally, I thank Gail Bayeta, who collaborated with me on collecting data for Study 1.

\section{Works Cited}

Adler, P. S. (2007). Beyond Hacker Idiocy: The Changing Nature of Software Community and Identity. In C. Heckscher \& P. S. Adler (Eds.), The Firm as a Collaborative Community: Reconstructing Trust in the Knowledge Economy (pp. 198258).

New York: Oxford University Press.

Adler, P. S., \& Heckscher, C. (2007). Towards Collaborative Community. In C. Heckscher \& P. S. Adler (Eds.), The Firm as a Collaborative Community: Reconstructing Trust in the Knowledge Economy (pp. 11105).New York: Oxford University Press.

Austin led the nation in percentage of small business growth. (2011). Austin Business Journal . Retrieved December 22, 2011, from http://www.bizjournals.com/austin/news/2011/12/01/austinledthenationinpercentageof.html Benkler, Y. (2006). The wealth of networks . New Haven, CT: Yale University Press.

Bradner, E., \& Mark, G. (2002). Why distance matters: effects on cooperation, persuasion and deception. CSCW '02: Proceedings of the 2002 ACM conference on Computer supported cooperative work (pp. 226235).

New York, NY, USA: ACM Press.

BurtonJones,A. (2001). Knowledge Capitalism (p. 264). New York: Oxford University Press.

Castells, M. (1993). The informational economy and the new international division of labor. In M.

Carnoy, M. Castells, S. S. Cohen, \& F. H. Cardoso (Eds.), The new global economy in the information age: Reflections on our changing world (pp. 1544).

University Park, PA:Pennsylvania State University Press.

Castells, M. (1996). Rise of The Network Society (p. 481). Malden, MA: Blackwell.

Castells, M. (1997). The power of identity . Malden, MA: Blackwell.

Castells, M. (2003). The Internet Galaxy: Reflections on the Internet, Business, and Society . New York, NY: Oxford University Press.

Castells, M. (2006). The Network Society: From Knowledge to Policy . (G. Cardoso \& M. Castells, Eds.) The Network Society: From Knowledge to Policy . Washington, D.C.: The Johns Hopkins

University Press; Center for Transatlantic Relations, JhuSais.

Castells, M. (2009). Communication Power . New York: Oxford University Press.

Corbin, J., \& Strauss, A. C. (2008). Basics of Qualitative Research: Techniques and Procedures for Developing Grounded Theory (Third edit., p. 400). Thousand Oaks, CA: Sage Publications, Inc. Daniels, H., Edwards, A., Engeström, Y., \& Ludvigsen, S. R. (Eds.). (2010). Activity Theory in Practice: Promoting Learning Across Boundaries and Agencies . New York: Routledge.

Drucker, P. F. (1994). PostCapitalist

Society . New York, NY: Harper Paperbacks.

Dwyer, C. J. (2011). Contingent Labor Management: The Evolution of Contemporary Contingent

Workforce . Framework (p. 33). Boston. Retrieved from

http://www.aberdeen.com/aberdeenlibrary/7023/RAcontingentlaborworkforce.aspx

Engeström, Y. (2008). From Teams to Knots: Studies of Collaboration and Learning at Work . New York: Cambridge University Press.

Engeström, Y. (2009). The future of activity theory: A rough draft. In A. Sannino, H. Daniels, \& K. Gutierrez (Eds.), Learning and expanding with activity theory (pp. 303328).

New York: 
Published in Technical Communication Quarterly 23(2), (2014), pp. 88-114;

DOI:10.1080/10572252.2013.797334

Cambridge.

Goffman, E. (1959). The Presentation of Self in Everyday Life . New York: Anchor.

Grabher, G. (2002). Cool projects, boring institutions: Temporary collaboration in social context.

Regional Studies , 36 (3), 205214.

doi:10.1080/00343400220122025

Guile, D. (2012). Interprofessional

working and learning: "Recontextualising" lessons from "project

work" for programmes of initial professional formation. Journal of Education and Work , 25 (1),

7999.Gygi, K., \& Zachry, M. (2010). Productive tensions and the regulatory work of genres in the

development of an engineering communication workshop in a transnational corporation. Journal

of Business and Technical Communication , 24 (3), 358381.

Latour, B. (1987). Science in action: How to follow scientists and engineers through society .

Philadelphia: Open University Press.

Malone, T. W. (2004). The future of work: How the new order of business will shape your organization, your management style and your life . Boston: Harvard Business School Press.

Mark, G., \& Su, N. M. (2010). Making infrastructure visible for nomadic work. Pervasive and Mobile Computing , 6 (3), 112.

Elsevier B.V. doi:10.1016/j.pmcj.2009.12.004

Midler, C. (1995). "Projectification” of the firm: The Renault case. Scandinavian Journal of

Management , 11 (4), 363375.

Miles, M. B., \& Huberman, A. M. (1994). Qualitative data analysis: An expanded sourcebook .

Thousand Oaks, CA: SAGE Publications.

Mueller, M. L. (2010). Networks and States: The global politics of Internet governance (p. 367).

Cambridge, MA: MIT Press.

Nardi, B. A., Whittaker, S., \& Schwarz, H. (2002). NetWORKers and their activity in intensional

networks. Computer Supported Cooperative Work , 11 , 205242.

Paretti, M. C., McNair, L. D., \& HollowayAttaway,

L. (2007). Teaching Technical Communication in

an Era of Distributed Work: A Case Study of Collaboration Between U.S. and Swedish Students.

Technical Communication Quarterly , 16 (3), 327352.

Russell, D. R. (1997). Rethinking genre in school and society: An activity theory analysis. Written

Communication , 14 (4), 504554.

Sannino, A., Daniels, H., \& Gutierrez, K. D. (Eds.). (2009). Learning and Expanding with Activity

Theory . New York: Cambridge University Press.

Smagorinsky, P. (2008). The Method Section as Conceptual Epicenter in Constructing Social Science

Research Reports. Written Communication , 25 (3), 389411.

doi:10.1177/0741088308317815

Spinuzzi, C. (2007). Guest Editor's Introduction: Technical Communication in the Age of Distributed

Work. Technical Communication Quarterly , 16 (3), 265277.

Lawrence Erlbaum Associates, Inc.

10 Industrial Avenue Mahwah, NJ 074302262USA.

Spinuzzi, C. (2011). Losing by Expanding: Corralling the Runaway Object. Journal of Business and

Technical Communication , 25 (4), 449486.

Spinuzzi, C. (2012). Working Alone, Together: Coworking as Emergent Collaborative Activity.

Journal of Business And Technical Communication , 26 (4).

Su, N., \& Mark, G. (2008). Designing for nomadic work. DIS 08 Proceedings of the 7th ACM

conference on Designing interactive systems . ACM Press.

Swarts, J. (2006). Coherent Fragments: The problem of mobility and genred information. Written

Communication , 23 (2), 173201.

Swarts, J. (2007). Mobility and composition: The architecture of coherence in nonplaces.

TechnicalCommunication Quarterly , 16 (3), 279309. 
Published in Technical Communication Quarterly 23(2), (2014), pp. 88-114;

DOI:10.1080/10572252.2013.797334

United States Census Bureau. (2011a). Population Estimates Data Sets. Retrieved July 25, 2011, a from http://www.census.gov/popest/datasets.html

United States Census Bureau. (2011b). 51 Information. Retrieved July 25, 2011, b from

http://www.census.gov/econ/census02/naics/sector51/51.htm

United States Census Bureau. (2011c). Nonemployer statistics. Retrieved July 25, 2011, c from

http://censtats.census.gov/cgibin/nonemployer/nonsect.pl

United States Small Business Association Office of Advocacy. (2011). Firm Data. Retrieved December

21, 2011, from http://archive.sba.gov/advo/research/data.html

Yamazumi, K. (2009). Expansive Agency in MultiActivity

Collaboration. In A. Sannino, H. Daniels,

\& K. D. Gutierrez (Eds.), Learning and Expanding with Activity Theory (pp. 212227).

NewYork: Cambridge University Press.

Zuboff, S., \& Maxmin, J. (2004). The support economy: Why corporations are failing individuals and the next episode of capitalism. New York: Penguin Books. 